\title{
The importance of shared understanding within football teams.
}

MALONE, M.K. and LORIMER, R.

2020

This is an Accepted Manuscript of an article published by Taylor \& Francis in Journal of Sport Psychology in

Action on 13-05-2020, available online: https://doi.org/10.1080/21520704.2020.1760982 
1 The Differences between a Group and a Team

Beauchamp, Maclachlan, and Lothian (2005) state that groups are complex entities

3 with members who contribute various personal psychological traits. Brannick, Roach, and

4 Salas (1993) and Carron and Hausenblas (1998) suggest that a team includes two or more

5 individuals that work together to achieve a common goal (i.e., winning a football match). The

6 terms group and team are used interchangeably and even though there are overlapping

7 characteristics (Sheard \& Kakabadse 2004), there are prominent variances demonstrates that

8 they are very different (Fisher \& Hunter 1997). The differences include teams requiring

9 higher task orientation (Lencioni 2007) and more purpose (Humphrey, Morgeson, \& Mannor,

10 2009) between their members compared to groups towards achieving the team's shared goals

11 (i.e., players within a football team working towards winning a match), a greater requirement

12 for structure (Stillman, Fletcher, \& Carr 2007), interdependency between members of a team

13 (Reimer, Park, \& Hinsz, 2006) compared to a group (Varma-Nelson \& Coppola, 2005) and

14 the need for team members to possess a familiarity of each other's roles (Mumford, Van

15 Iddekinge, Morgeson, \& Campion, 2008) to coordinate their performance (Cannon-Bowers \&

16 Bowers, 2006). This suggests team members require knowledge of each other's role to be

17 able to coordinate their actions.

Cannon-Bowers and Bowers (2006) highlight the importance of team interdependence

20 within football, that is centred on members in various sub-teams working together to

21 coordinate their actions, whereas a member of a gymnastics team is unlikely to support another member during their performance. Sub-teams are required to perform their own roles that contribute to an effective team performance (Marsh, Richardson, Baron, \& Schmidt

24 2006; Duarte et al., 2012). Lyle (2002) states that within performance coaching in team sport, 25 the different requirements for each role require to be developed through a thoroughly 
1 prepared training programme by the coach to help team members to understand their role and

2 how this is crucial to the team's performance. For example, in football team members need to

3 understand how what their role is within their own sub-team to facilitate an effective team

4 performance (i.e. scoring goals or not conceding goals).

5

6

A key consideration should be to examine how team members share the knowledge of each other's roles between each sub-team to coordinate their actions within team sport.

Therefore, it is crucial to investigate what shared understanding is, how it develops within a team, why it should be an important consideration for coaches in team sports and the impact this knowledge has on team performance.

What is Shared Understanding?

Shared understanding is when two or more people think synergistically (i.e. share coordinated thoughts) during specific scenarios based on prior experience performing together (Blickensderfer et al., 2010). Eccles and Tenenbaum (2004) state that for teams to be able to perform effectively together, their members require a knowledge of each other's skills and likely actions. This suggests that players must understand the abilities of their team members and use this knowledge to be able to read situations in the same way. Shared situational awareness can be defined as a relevant and accurate view of the environment and this provides a common picture between members of a team (Nofi, 2000). If team members did not have shared situational awareness, they would be unable to coordinate their actions (Adamu, Emmitt, \& Soetanto, 2015) leading to an uncoordinated performance. However, in addition to having the ability to read situations in the same way, it is also crucial to have a knowledge of why each player thinks this is the optimal action to understand each other's in an effective performance (i.e. shared understanding). When considering an attacking set piece 
1 for example, each team member would need to be able to analyse a situation in the same way,

2 have an appreciation of each other's abilities as well as the likely actions of others in the

3 team. If team members did not have a shared situational awareness, they would potentially

4 make the same movements (rather than perform their own individual roles) and the set-piece

5 would be unsuccessful. However, if player's shared understanding and their situational

6 awareness was accurate, the chances of performing this set piece successfully would increase.

7 Therefore, it is crucial for team members to interpret situations related to performance based

8 on accurate information to be able to coordinate their performance. Silva, Garganta, Araújo,

9 Davids, and Aguiar (2013) state that shared understanding can take time and experience

10 performing together to develop effectively. However, it is important to consider how this

11 knowledge is held and distributed within a team.

12

13 Shared Mental Models as a Foundation of Shared Understanding Marks, Zaccaro, and Mathieu (2000) explain that a shared mental model is a set of

15 knowledge structures that are shared between two or more people to enable a more effective 16 performance (Cannon-Bowers, Salas and Converse 1993; Steiner, Macquet, \& Seiler, 2017).

17 Mathieu et al. (2000) state that the shared understanding is facilitated between multiple people (i.e. a football team) through an effective shared mental model. Within a football team for example, team members are required to think synergistically to work effectively together 20 as a team.

22 An effective shared mental model enables the sharing of information (shared understanding) 23 and facilitates understanding between team members (Mathieu et al., 2000). Cannon-Bowers 24 et al. (1993) and Mathieu et al. (2000) discuss that there are multiple types of shared mental 25 models rather than just one. Cannon-Bowers and Salas (2001) states that shared knowledge is 
1 made up of four separate areas that include task-specific knowledge, task-related knowledge,

2 knowledge of teammates and attitudes. This suggests that there are different types of

3 knowledge that can be shared within the team. This is because different situations may

4 require a combination of separate different knowledge structures between team members. For

5 example, if a team is required to focus on completing a task like scoring a goal in order to

6 equalise late in a game, they would tap into one type of shared mental model (a task work

7 mental model). Jonker, van Riemsdijk, and Vermeulen (2010) state that the task work shared

8 mental model is linked to the team's task that must be carried out effectively. For example, a

9 team would adopt this shared mental model when they were looking to score a goal in final

10 stages of a match, rather than working effectively together and how the goal may be scored.

11 However, a shared mental model which is more focused on how the team functions (a teamwork mental model) could be used by players that has new players in order to build their understanding. This is because a teamwork mental model is focused on how the team

14 functions and considers each player's skills and preferred actions (Jonker et al., 2010). When new players start to play together, team members would use this type of shared mental model to learn how each other will react in certain scenarios, in order to perform together. However,

17 Salas, Shuffler, Thayer, Bedwell, and Lazzara (2015) highlight the importance of both successful task work and teamwork in relation to an effective team performance, with both being co-dependent on each other. For example, teams who have high task expertise but do not work well together are unlikely to be able to perform effectively together.

22 A key consideration for success of performance in any situation is the efficiency of the shared mental model that team members access. For instance, if some team members do not have an accurate understanding of certain players and their roles, their teamwork mental model will not be effective, and the team will not know what each other are doing in certain scenarios. 
1 This can result in players choosing actions that may result in the loss of possession of the ball

2 (i.e., one player may attempt to pass to the striker who is expecting a pass over the opposition

3 defence). In this situation the striker would not retain the ball, increasing the chance of the

4 opposition taking possession of the ball, reducing the chance of scoring a goal. Williamson

5 and Cox (2014) state that it can take time to build an effective shared mental model between

6 team members, in addition to experience performing together in order to develop. Ellis and

7 Davidi (2005) highlight the importance of learning from mistakes in training to be able to

8 develop better strategies for performing together, enhancing their shared mental model.

9 Blickensderfer et al. (2010) and Gershgoren et al. (2016) suggest that experience performing

10 together is fundamental to developing understanding between team members. Salas et al.

11 (2015) elaborate on this suggestion that teams who have knowledge of how to perform the necessary task and can perform together are more likely to perform better. In reference to the above set piece example, for team members to be able to execute the corner effectively and increase their chance of scoring, they would need to work together to practice their individual 15 roles in training.

Why is Shared Understanding Important in Football?

highlight the importance of shared understanding in relation to improving overall team performance. Cannon-Bowers, and Salas (2001) and Fiore, Salas, Cuevas, and Bowers (2003) state that accurate shared understanding between team members requires a knowledge of other roles within a team (Reimer et al., 2006) and can influence the effective performance of the overall team. For example, if the defensive players have accurate knowledge of the attacking roles within their team, they would be able to use a mixture of their teamwork and 
1 task work shared mental model to more effectively transition possession of the ball to the

2 attackers.

4 However, this exchange of knowledge is only possible through an effective shared mental

5 model that is developed over time performing together (Mathieu et al., 2000). For instance, if

6 the whole team practice transitioning the ball forward during training sessions, defenders will

7 know what type of pass is best to give certain attackers (i.e., a ball over the top of the

8 opposition defence or to the attacker's feet). This knowledge will help the team keep

9 possession of the ball, increasing the effectiveness of their performance and their chance of

10 scoring goals. In addition to developing an understanding of what team members are likely to

11 do and what their preferences are, Salas, Sims and Burke (2005) state that within a successful

12 team, members have specific knowledge of each other that allow players to modify the

13 workload between team members (i.e. backup behaviours) if there are situations that require

14 it.

16 The following section outlines the benefits of an effective shared mental model for team

17 performance in football and shared understanding between players. In addition to stating the

18 benefits of shared understanding between football players, the methods of how to develop

19 shared understanding between team members will be detailed and analysed.

21 Benefits of Increased Shared Understanding

Improvements to the Methods of Communication between Players

When team members perform more regularly together, their shared understanding will

24 develop (Gershgoren et al., 2016) and their ability to use more effective methods of

25 communication will improve. Salas et al. (2005) further state that more effective methods of 
1 communication are formed through an efficient shared mental model and this can lead to

2 improvements in performance (i.e. adaption to perform backup behaviours successfully if the

3 situation requires it). Cooke, Gorman, Duran, and Taylor (2007) suggest that when team

4 members become more familiar with one another, their methods of communication become

5 more streamlined and less-time consuming (i.e., they will be able to determine what certain

6 shouts mean). For instance, when players get to know each other and have more accurate

7 shared understanding, they may begin to use non-verbal methods of communication including

8 looks and gestures (Onağ \& Tepeci, 2014). For example, when defensive line is performing

9 an offside trap, effective communication methods will assist each player's focus and they are

10 able to use specific shouts (verbal) or gesturing (non-verbal) to communicate that they should

11 be doing. Onağ and Tepeci (2014) state that in this situation, the player's actions will be

12 quicker and more efficiently compared to team members who are unable to communicate

13 effectively together. Eccles and Tenenbaum (2004) and Cooke et al. (2007) suggest that to

14 develop effective communication methods, team members must have an accurate

15 understanding of each member, which is developed through experience performing together.

16 This suggests that effective methods of communication can be established between team

17 members through an accurate understanding between the players. Therefore, it would be

18 important to consider how shared understanding is able to improve within team sport.

20 How to Improve Shared Understanding between Team Members

Blickensderfer et al. (2010) state that there are several factors that can facilitate the development of shared understanding between team members. This section will establish the benefits of shared understanding between football players and suggest three methods that coaches can implement as part of their training schedule to improve overall team performance. Salas, Nichols, and Driskell (2007) highlight the importance of methods of 
1 team training and how different experiences with team members can improve their

2 knowledge of one and other.

4 Give Players Guided Experience Performing Together

A method for developing shared understanding between football players involves players having more experience performing together (Blickensderfer et al., 2010). Salas, DiazGranados, Weaver and King (2008) suggest that team training gives members the opportunity to practice game related scenarios and develop their skills together however, this must be guided by the team's coach (i.e. training focused on a different formation for the next match) as unguided experience does not guarantee learning (Salas et al., 2008). Salas et al. (2007) advocate that if someone (i.e. a coach) guides the experience this can lead to the development of an effective shared mental model between athletes and an efficient team performance. Deakin and Cobley (2003) suggest that coaches can give team members the opportunity to develop an opponent specific shared mental model based on the team that they are against. Team members must adapt to the actions of their opposition as well as their own team (Tenenbaum, 2003). For example, a team close to the relegation zone would adopt a different shared mental model against a team near the top of the league (more defensive) compared to a team below them (more attacking). Therefore, the team's coach can create scenarios within training prior to this match to prepare their team to perform effectively against the opposition by making it more difficult for them to predict how they are going to perform.

3 The above example demonstrate that a different shared mental model may be required in different situations depending on external circumstances like their opposition (Reimer et al., 2006) but this must be implemented by the coach. This approach from a coach can prepare 
1 their players for several different situations, this can reduce the likelihood of the opposition

2 being able to predict how the team is going to play as they do not have one style of play for

3 every match. Salas et al. (2005) further state that a crucial effective understanding between

4 players, through specific training, can develop a knowledge of how to perform backup

5 behaviours if required. For example, if a defender is caught out of position, a successful team

6 with an effective shared mental model would allow for another player to cover for this

7 defender and perform their role until they are back in position. This situation can be achieved

8 during specific training, to be implement during a game.

10 However, Deakin and Cobley (2003) and Gabbett (2006) highlight that a coach has a crucial

11 role within players gaining specific experience together and improving the learning experience training to prepare for competition. Williamson and Cox (2014) illustrate the importance of experience together and state that accurate expectations of others are possible through team members performing with each other. In this situation, players will further their knowledge of their own role, understand other team member's required actions and perform better together. Salas et al. (2008) recommend that relevant and detailed feedback is a crucial part of team training and can reinforce desired behaviours for each player. Ellis and Davidi (2005) state that specific and organised feedback on their performance can be beneficial for team members. For example, feedback in the form of debriefs from a coach on theoretical situations could also be used during training sessions to reinforce off-field training methods.

21 Salas et al. (2015) highlight the importance of coaches using debriefs within training to give athletes opportunity to reflect on positive and negative aspects of performance. This experience can assist reinforcement of learning help to improve their decision making for

24 future performances. Tannenbaum and Cerasoli (2013) advocate that if coaches use debriefs effectively, the team's performance can improve in the future by up to $25 \%$. This method 
1 gives players experience performing together, with a debrief from the coach they are more

2 knowledgeable of what to do in certain situations within their team.

4 As stated within The Model of Team Cohesion for Sports (Carron \& Brawley 2008) task

5 cohesion is a crucial component in relation to team cohesion. Task cohesion can be

6 developed through participants performing together and gaining experience with each other

7 in a practical environment (Carron \& Brawley 2008), further developing their knowledge of

8 each other and improve their ability to perform more effectively together (Williamson \& Cox,

9 2014). Salas et al. (2007) advise that through team training, team members can get experience

10 together and develop solutions to errors in performance. Blickensderfer et al. (2010)

11 recommend that team members within tennis doubles, choose their actions based on their

12 previous experience in similar situations with their team. Previous experience together is also

13 crucial for developing accurate decision making within team sports. For example, a coach

14 should select their squad and allow the sub-teams (i.e. two strikers) to learn how each other

15 perform in certain situations, as proposed by Williamson and Cox (2014) with the added

16 pressure of competition. This is an effective method for players to see how each other react in

17 various situations and create an accurate understanding of the actions of others and as

18 Gershgoren et al. (2016) suggest, this can lead to a better team performance.

\section{Experience Together Outside of Football}

In addition to experience in a football setting, coaches should encourage players to spend time together outside of a sporting context. Carron and Brawley (2008) state that social cohesion is a central component when examining team cohesion and can facilitate the

24 development of shared understanding between players in the team. This will help develop

25 their understanding within a sporting setting because team members who do not get along 
1 with one another are less likely to perform effectively together (O'Neill, Allen, \& Hastings,

2 2013). Pescosolido and Saavedra (2012) reveal that team members that spend some of their

3 spare time together can improve the effectiveness of their relationship and their ability to

4 work efficiently as a team. Examples of different team building activities could include crazy

5 golf, playing video games or going out for a meal with the focus being on improving their

6 relationship. This approach can also support team members to understand and outline the

7 various roles within a team (Shuffler, Burke, Kramer \& Salas, 2013). However, Salas (2015)

8 suggest that this method may not always have benefit for team members.

10 Salas et al. (2008) highlight that teams can benefit from taking part in team building activities

11 together as this can develop interpersonal relationships and improve social interactions

12 between team members however, team training strategies can be more effective. Therefore, it

13 would be beneficial for team performance if coaches to encourage players to spend time

14 together in their own time. However, as illustrated within The Model of Team Cohesion for

15 Sports (Carron \& Brawley 2008), both social and task cohesion are required for a team to be

16 able to effectively perform together.

A Combination of Both

As suggested in the previous two sections, both experience performing together and

20 spending time together outside of the sport are an important way of developing shared

21 understanding between team members. Salas et al. (2008) suggest that effective training does

22 not just happen overnight and can take time to develop. Carron, and Brawley's Model of

23 Team Cohesion for Sports (2008) state that a mix of both task and social cohesion (in a

24 sporting environment and a social setting), would be beneficial to a team's ability to work

25 effectively together. Therefore, experience in football and outside of the sport is an important 
1 recommendation to coaches who have the desire to improve their team's shared

2 understanding.

$4 \quad$ Greater Knowledge of Other Roles in a Team

6 player's roles in the team, this can improve the chances of being able to work together

7 effectively together. Salas et al. (2015) state that cross-training is a method of team training

8 that involves coaches rotating players around different positions, leading to improvements in

9 team performance and a greater understanding of other roles. This is because this scenario

10 will give players an appreciation of what others will do in certain roles in the team (Marks et

11 al., 2002), cam allow team members to perform backup behaviours if required (Salas et al.,

12 2005) and facilitate a more effective team performance. Cruickshank and Collins (2012)

13 suggest that teams are made up of several different sub-teams based on team member's

14 positions. For example, if the central midfielders in a football team have the knowledge that

15 their central defenders are likely to win headers against a certain team when they challenge

16 for the ball in the air, they can access their team work mental model and move into a position

17 on the pitch where they think the ball is most likely to land. However, if the defenders are

18 playing against attackers who are likely to stop the defender winning a header, they will be

19 able to coordinate their behaviour to respond to this situation. Through an increase in

20 understanding of each other's roles, players can accurately predict what other players will do

21 next (Jonker et al., 2010) and can perform backup behaviours if they need to (Salas et al. 2005). For example, if the central midfielders had knowledge of what their central defenders are likely to do through an effective teamwork mental model, then they are more likely to be

24 able to predict what they are likely to do. This allows players to get into a position where they

25 think that the football will land in order to perform their own chosen action. However, 
1 experience performing together is crucial to build the knowledge between team members

2 (Eccles \& Tenenbaum, 2004).

\section{$4 \quad$ Discuss Hypothetical Scenarios as Part of Training}

Another suggestion for improving shared understanding between players is to discuss

6 hypothetical football-based situations with players. This gives players another form of

7 experience and can learn what each other are thinking in certain situations and helps to

8 prepare for different situations that may be required when performing against different teams,

9 leading to that team's actions being less predictable by an opposition. For example, if a team

10 has prepared multiple strategies through team training led by their coach, they will be able to

11 effectively use their knowledge of different strategies through their shared understanding against an opposition. As recommended by Silva et al. (2013), experience together is a crucial factor in developing shared understanding between team members. Therefore, if there was another method that could give players extra experience, team members would be able to develop shared understanding over a shorter period, allowing team members to perform more effectively together quicker. Salas et al. (2008) suggest that effective team training must include conveying knowledge in a classroom setting in addition to practical scenarios.

Silva et al. (2013) conject thinking the same in specific situations can lead to a more effective team performance. For example, through using a tactics board a coach can design specific scenarios and ask their players to write down what their thoughts are and what actions they think some of the players should take. This can lead to an open discussion with team members to see what each player thinks and see if they possess parallel thoughts. Implementing this type of training can alleviate any issues around injured players potentially missing out on experience performing together for example. Taking part in hypothetical 
1 scenarios will mean that players can still develop their understanding of one and other

2 without making their injury worse.

4 Marks, Zaccaro, and Mathieu (2000) reveal that team members possess a shared mental

5 model where they share their thoughts based on previous experience performing together.

6 This is an effective way of opening a dialog with players and allows everyone to see what the

7 rest of their team thinks in certain situations. This type of activity can improve the team's

8 shared understanding and give them an appreciation of what is required in certain roles.

9 Reimer et al. (2006) and Salas et al. (2015) evidence that to perform effectively together,

10 team members require an understanding of players who perform different roles and how they

11 are likely to react in certain situations.

Encourage an Open Discussion between Coaches and Players

Mathieu et al. (2000) highlight the importance of having knowledge of other roles in a team and having efficient shared understanding between their members to perform effectively together. This can lead to developments in communication between team members, through and effective shared mental model, and can facilitate improvements to performance like improved coordination and improved ability to perform backup behaviours Salas et al. (2005). This approach does not have to be based on tactics boards and can involve different methods such as a focus group with players to talk about situations or watch videos of a series of play then have a discussion with each other. Blickensderfer et al. (2010) advocate this is fundamental to the development of shared understanding between players as the knowledge of how their team members think and act in specific situations. 
1 Give Players the Knowledge to Allow for the Prediction of Actions

Through open discussions with players (i.e. theoretical scenarios off-field or during

3 situation-based training) team member's understanding of each other and their own roles

4 within the team will increase. Mach, Dolan, and Tzafrir (2010) suggest that understanding

5 other roles within a team can allow for a more effective team performance. This is an

6 important consideration for coaches as this approach can lead to players more accurately

7 being able to predict what each other are going to do and prefer to do at any one time.

8 Mathieu et al. (2000) state that team members are more successful at predicting the actions of

9 their team members if they have the knowledge of each other's abilities and are more likely

10 to produce a more coordinated performance. For instance, using these types of scenarios

11 before or during training sessions, while holding open discussions will give players the understanding of what each other are thinking and translate that to real world situations. This can allow team members to be able to perform backup behaviours (Salas et al., 2005) if

14 players are out of position. In addition to this, team members will learn what other players

15 prefer to do during a match (i.e. having the ball to be passed to their feet to move the ball on

16 quickly or the ball played into an open space to run onto to then score a goal). To conclude, this training approach will give team members the knowledge of what each other may prefer to do in specific situations - based on player discussions - and can improve their accuracy of

19 predicting these actions and lead to a more effective performance.

\section{Conclusion}

In a team sport like football it is important to acknowledge the link between shared understanding between team members and an effective team performance (Gershgoren et al.,

24 2016). Teams who have experience performing together will be able to more accurately

25 predict what each other will do in certain situations (Mathieu et al., 2000) and be able to 
1 produce a more efficient team performance including increased coordination and the

2 capability of performing backup actions if required (Salas et al., 2005). One of the

3 fundamental parts to this is team members who understand each other's role and likely

4 actions (Silva et al., 2013). Coaches who facilitate shared understanding between their

5 players can improve methods of communication between team members at the same time as

6 improving their ability to perform effectively together. However, coaches must be able to

7 give their players experience of performing together to be able to build up an accurate

8 understanding. That can range from pairing players up in training to discussing hypothetical

9 scenarios with their team in order to improve their understanding of specific roles within the

10 team and potential required actions. Adopting these methods as part of a training schedule

11 will benefit players within a team by developing shared understanding between players to

12 help produce a more effective team performance over a shorter period. 


\section{Reference List}

Adamu, Z. A., Emmitt, S., \& Soetanto, R. (2015). Social BIM: Co-creation with shared situational awareness. Journal of Information Technology in Construction (ITcon), 20(16), 230-252.

Beauchamp, M. R., Maclachlan, A., \& Lothian, A. M. (2005). Communication within sport teams: Jungian preferences and group dynamics. The Sport Psychologist, 19(2), 203-220.

Blickensderfer, E. L., Reynolds, R., Salas, E., \& Cannon-Bowers, J. A. (2010). Shared expectations and implicit coordination in tennis doubles teams. Journal of Applied Sport Psychology, 22(4), 486-499.

Bourbousson, J., Feigean, M., \& Seiler, R. (2019). Team cognition in sport: How current insights into how teamwork is achieved in naturalistic settings can lead to simulation studies. Frontiers in psychology, 10, 2082.

Brannick, M. T., Roach, R. M., \& Salas, E. (1993). Understanding team performance: A multimethod study. Human Performance, 6(4), 287-308.

Cannon-Bowers, J. A., \& Bowers, C. (2006). Applying work team results to sports teams: Opportunities and cautions. International Journal of Sport and Exercise Psychology, 4(4), 447-462.

Cannon-Bowers, J. A., \& Salas, E. (2001). Reflections on shared cognition. Journal of Organizational Behavior: The International Journal of Industrial, Occupational and Organizational Psychology and Behavior, 22(2), 195-202. 
Carron, A. V., \& Brawley, L. R. (2008). Group dynamics in sport and physical activity. In T. Horn (Ed.), Advances in sport psychology (pp.213-237). Champaign, IL: Human Kinetics

Carron, A. V., \& Hausenblas, H. A. (1998). Group dynamics in sport (2nd edn). Morgantown, WV: Fitness Information Technology. Letting the social and cognitive merge, 311 .

Cannon-Bowers, J.A., Salas, E., \& Converse, S.A. (1993). Shared mental models in expert team decision making. In N.J. Castellan (Ed.), Individual and group decision making: Current issues (pp. 221-246). Hillsdale, NJ: Erlbaum.

Cooke, N. J., Gorman, J. C., Duran, J. L., \& Taylor, A. R. (2007). Team cognition in experienced command-and-control teams. Journal of Experimental Psychology: Applied, 13(3), 146.

Cruickshank, A., \& Collins, D. (2012). Culture change in elite sport performance teams: Examining and advancing effectiveness in the new era. Journal of Applied Sport Psychology, 24(3), 338-355.

Deakin, J. M., \& Cobley, S. (2003). A search for deliberate practice: An examination of the practice environments in figure skating and volleyball. In Expert performance in sports: Advances in research on sport expertise (pp. 115-135). Champaign IL: H

Duarte, R., Araújo, D., Freire, L., Folgado, H., Fernandes, O., \& Davids, K. (2012). Intra-and inter-group coordination patterns reveal collective behaviors of football players near the scoring zone. Human Movement Science, 31(6), 1639-1651. 
Eccles, D. W., \& Tenenbaum, G. (2004). Why an expert team is more than a team of experts: A social-cognitive conceptualization of team coordination and communication in sport. Journal of Sport and Exercise Psychology, 26(4), 542-560.

Ellis, S., \& Davidi, I. (2005). After-event reviews: Drawing lessons from successful and failed experience. Journal of Applied Psychology, 90(5), 857.

Fiore, S. M., Salas, E., Cuevas, H. M., \& Bowers, C. A. (2003). Distributed coordination space: toward a theory of distributed team process and performance. Theoretical Issues in Ergonomics Science, 4(3-4), 340-364.

Fisher, S. G., \& Hunter, T. A. (1997). Team or group? Managers' perceptions of the differences. Journal of Managerial Psychology.

Gabbett, T. J. (2006). Skill-based conditioning games as an alternative to traditional conditioning for rugby league players. Journal of Strength and Conditioning Research, 20(2), 309 .

Gershgoren, L., Basevitch, I., Gershgoren, A., Brill, Y. S., Schinke, R. J., \& Tenenbaum, G. (2016). Expertise in soccer teams: A thematic inquiry into the role of shared mental models within team chemistry. Psychology of Sport and Exercise, 24, 128-139.

Humphrey, S. E., Morgeson, F. P., \& Mannor, M. J. (2009). Developing a theory of the strategic core of teams: A role composition model of team performance. Journal of Applied Psychology, 94(1), 48.

Jonker, C. M., Van Riemsdijk, M. B., \& Vermeulen, B. (2010, August). Shared mental models. In International Workshop on Coordination, Organizations, Institutions, and Norms in Agent Systems (pp. 132-151). Springer, Berlin, Heidelberg. 
Lencioni, P. M. (2007). The five dysfunctions of a team: Participant Workbook (Vol. 8). John Wiley \& Sons.

Lyle, J. (2002). Sports coaching concepts: A framework for coaches' behaviour. London: Routledge.

Mach, M., Dolan, S., \& Tzafrir, S. (2010). The differential effect of team members' trust on team performance: The mediation role of team cohesion. Journal of Occupational and Organizational Psychology, 83(3), 771-794.

Marks, M. A., Sabella, M. J., Burke, C. S., \& Zaccaro, S. J. (2002). The impact of crosstraining on team effectiveness. Journal of Applied Psychology, 87(1), 3.

Marks, M. A., Zaccaro, S. J., \& Mathieu, J. E. (2000). Performance implications of leader briefings and team-interaction training for team adaptation to novel environments. Journal of applied psychology, 85(6), 971.

Marsh, K. L., Richardson, M. J., Baron, R. M., \& Schmidt, R. C. (2006). Contrasting approaches to perceiving and acting with others. Ecological Psychology, 18(1), 1-38.

Mathieu, J. E., Heffner, T. S., Goodwin, G. F., Salas, E., \& Cannon-Bowers, J. A. (2000). The influence of shared mental models on team process and performance. Journal of applied psychology, 85(2), 273.

Mumford, T. V., Van Iddekinge, C. H., Morgeson, F. P., \& Campion, M. A. (2008).

The Team Role Test: Development and validation of a team role knowledge situational judgment test. Journal of Applied Psychology, 93(2), 250.

Nofi, A. A. (2000). Defining and measuring shared situational awareness (No. CRMD0002895. A1). Center For Naval Analyses AlexandriA VA. 
Onağ, Z., \& Tepeci, M. (2014). Team effectiveness in sport teams: The effects of team cohesion, intra team communication and team norms on team member satisfaction and intent to remain. Procedia-Social and Behavioral Sciences, 150, 420-428.

O'Neill, T. A., Allen, N. J., \& Hastings, S. E. (2013). Examining the "Pros" and "Cons" of Team Con flict: A Team-Level Meta-Analysis of Task, Relationship, and Process Conflict. Human Performance, 26(3), 236-260.

Pescosolido, A. T., \& Saavedra, R. (2012). Cohesion and sports teams: A review. Small Group Research, 43(6), 744-758.

Reimer, T., Park, E. S., \& Hinsz, V. B. (2006). Shared and coordinated cognition in competitive and dynamic task environments: An information-processing perspective for team sports. International Journal of Sport and Exercise Psychology, 4(4), 376-400.

Salas, E., DiazGranados, D., Weaver, S. J., \& King, H. (2008). Does team training work? Principles for health care. Academic Emergency Medicine, 15(11), 1002-1009.

Salas, E., Nichols, D. R., \& Driskell, J. E. (2007). Testing three team training strategies in intact teams: A meta-analysis. Small Group Research, 38(4), 471-488.

Salas, E., Shuffler, M. L., Thayer, A. L., Bedwell, W. L., \& Lazzara, E. H. (2015). Understanding and improving teamwork in organizations: A scientifically based practical guide. Human resource management, 54(4), 599-622.

Salas, E., Sims, D. E., \& Burke, C. S (2005) Is there a "big five" in team work? Small Group Research, 36, 455-499.

Sheard, A. G., \& Kakabadse, A. P. (2004). A process perspective on leadership and team development. Journal of Management Development, 23(1), 7-106. 
Shuffler, M. L., Burke, C. S., Kramer, W. S., \& Salas, E. (2013). Leading teams: Past, present, and future perspectives. In M. G. Rumsey (Ed.), Oxford library of psychology. The Oxford handbook of leadership (p. 144-166). Oxford University Press.

Silva, P., Garganta, J., Araújo, D., Davids, K., \& Aguiar, P. (2013). Shared knowledge or shared affordances? Insights from an ecological dynamics approach to team coordination in sports. Sports Medicine, 43(9), 765-772.

Steiner, S., Macquet, A. C., \& Seiler, R. (2017). An integrative perspective on interpersonal coordination in interactive team sports. Frontiers in psychology, 8, 1440. Stillman, J. A., Fletcher, R. B., \& Carr, S. C. (2007). Netball team members, but not hobby group members, distinguish team characteristics from group characteristics. Journal of Sport and Exercise Psychology, 29(2), 253-266.

Tenenbaum, G. (2003). Expert athletes. An integrated approach to decision making. In J. L. Starkes \& K. A. Ericcson (Eds.), Expert performance in sport: Advances in research on sport expertise (pp. 191-215). Champaign, IL: Human Kinetics. Tannenbaum, S. I., \& Cerasoli, C. P. (2013). Do team and individual debriefs enhance performance? A meta-analysis. Human Factors: The Journal of the Human Factors and Ergonomics Society, 55(1), 231-245.

Varma-Nelson, P., \& Coppola, B. P. (2005). Team learning. In Chemist's guide to effective teaching (pp. 155-169). Saddle River, NJ: Pearson, 2005; 155-169.

Williamson, K., \& Cox, R. (2014). Distributed cognition in sports teams: Explaining successful and expert performance. Educational Philosophy and Theory, 46(6), 640654. 